\title{
Objectively measured preoperative physical activity is associated with time to functional recovery after hepato-pancreato- biliary cancer surgery: a pilot study
}

${\text { Caspar F. Mylius }{ }^{1 *}\left(\mathbb{D}, \text { Wim P. Krijnen }{ }^{1} \text {, Tim Takken², Daan J. Lips }{ }^{3}, \text { Hasan Eker }^{4} \text {, Cees P. van der Schans }\right.}^{1,5,6}$ and Joost M. Klaase ${ }^{7}$

\begin{abstract}
Background: Surgical resection is currently the cornerstone of hepato-pancreato-biliary (HPB) cancer treatment. A low preoperative aerobic fitness level has been identified as a modifiable risk factor associated with complications after major abdominal surgery. A person's aerobic fitness is influenced by performing moderate to vigorous physical activity (MVPA). This study aims to determine the activity monitor measured levels of MVPA performed among patients on the waiting list for HPB cancer surgery and their association with postoperative outcomes.

Methods: A prospective, observational multi-center cohort pilot study was conducted. Patients enlisted for resection surgery on suspicion of HPB (pre)malignancy were enrolled. Performed MVPA was measured by an Actigraph wGT3XBT. Additionally, aerobic fitness was measured via the Incremental Shuttle Walk Test, and (post)operative variables were collected from the electronic patient files. The association between MVPA and the pre- and postoperative variables was determined by univariate and multivariable (logistic) robust regression.

Results: A total of 38 participants, median age 66.0 (IQR 58.25-74.75) years, were enrolled. The median daily MVPA was 10.7 (IQR 6.9-18.0) min; only 8 participants met the Dutch MVPA guidelines. Participant's age and aerobic fitness were associated with MVPA by multivariable statistical analysis. Time to functional recovery was 8 (IQR 5-12) days and was associated with MVPA and type of surgery (major/minor) in multivariable analysis.
\end{abstract}

Conclusion: Seventy-six percent of patients enlisted for resection of HPB (pre)malignancy performed insufficient MVPA. A higher level of MVPA was associated with a shorter time to functional recovery.

Keywords: Hepato-pancreato-biliary cancer, Perioperative, Preoperative, Physical activity, Time to functional recovery

\footnotetext{
*Correspondence: c.f.mijlius@pl.hanze.nl

'Research Group Healthy Ageing, Allied Health Care and Nursing, Hanze

University of Applied Sciences, Petrus Driessenstraat 3, 9714 CA Groningen,

The Netherlands

Full list of author information is available at the end of the article
}

(c) The Author(s). 2021 Open Access This article is licensed under a Creative Commons Attribution 4.0 International License, which permits use, sharing, adaptation, distribution and reproduction in any medium or format, as long as you give appropriate credit to the original author(s) and the source, provide a link to the Creative Commons licence, and indicate if changes were made. The images or other third party material in this article are included in the article's Creative Commons licence, unless indicated otherwise in a credit line to the material. If material is not included in the article's Creative Commons licence and your intended use is not permitted by statutory regulation or exceeds the permitted use, you will need to obtain permission directly from the copyright holder. To view a copy of this licence, visit http://creativecommons.org/licenses/by/4.0/ The Creative Commons Public Domain Dedication waiver (http://creativecommons.org/publicdomain/zero/1.0/) applies to the data made available in this article, unless otherwise stated in a credit line to the data. 


\section{Introduction}

Hepato-pancreato-biliary (HPB) cancer is a frequently diagnosed disease with an incidence of 248,800 patients diagnosed with HPB cancer in Europe in 2018, of which pancreatic cancer constituted the majority with 132,600 diagnoses (Ferlay et al. 2018). Since advancing age of the population is the most important factor contributing to the incidence of pancreatic cancer, the incidence and the average age of HPB cancer patients are set to increase in the coming years due to increasing life expectancy (Bray et al. 2018; Kontis et al. 2017). Surgical resection and adjuvant therapy are currently the cornerstone of treatment for HPB cancer (Kommalapati et al. 2018). Currently, approximately $20-30 \%$ of patients develop major postoperative complications which lead to increased length of hospital stay (LOS), decreased postoperative quality of life, and delay to chemotherapy (Pinto et al. 2016; Pearse et al. 2012; Kumar and Garcea 2018). Since complications and mortality rates following pancreatic and liver surgery increase with advancing age (Raill 2009), identifying modifiable risk factors in HPB cancer patients may help to reduce postoperative complications, LOS, and hospital costs (Straatman et al. 2015).

Preoperative aerobic fitness level has been identified as a modifiable risk factor in a variety of patients who need surgery (Snowden et al. 2010; Simões et al. 2018; Van Beijsterveld et al. 2019). A person's aerobic fitness reflects the physiological reserve available to endure the physical stress of surgery and postoperative recovery (Levett and Grocott 2015). Low preoperative aerobic fitness is associated with negative postoperative outcomes such as prolonged LOS and increase in incidence of unplanned readmissions, morbidity, and mortality after major intraabdominal surgery (Moran et al. 2016a; Chandrabalan et al. 2013). A person's aerobic fitness is influenced by his or her physical activity (PA) level (Hallal et al. 2012; Chastin et al. 2018). Consequently, current (inter)national guidelines for PA advocate to spend at least $150 \mathrm{~min}$ per week in activities with a moderate to vigorous intensity (MVPA) (Weggemans et al. 2018; WHO 2009).

Multiple studies investigated the relation between preoperative (self) reported PA levels and outcome after surgery concluding that a higher preoperative level of PA is not significantly associated with the presence of postoperative complications (OR=2.60; 95\% $\mathrm{CI}=0.59$ to 11.37$)$. However, it has been previously reported that PA is significantly associated with shorter LOS following abdominal surgery $(\mathrm{OR}=3.66$; $95 \% \mathrm{CI}=1.38$ to 9.6) (Steffens et al. 2019). Nevertheless, correlations between self-reported PA and actual PA are generally low-to-moderate and ranging from $R=-0.71$ to 0.96 (Colley et al. 2019; Prince et al. 2008). Furthermore, previous studies have demonstrated that cancer patients overestimate their self-reported PA level when compared to objective measures (Vassbakk-Brovold et al. 2016).
Therefore, insight into the level of actual, objectively measured, PA and subsequent postoperative outcomes in patients scheduled for HPB cancer surgery is needed. This study aims to determine the activity monitor measured levels of MVPA performed among patients on the waiting list for HPB cancer surgery. Additionally, the secondary aim of the study is to determine the association between preoperative MVPA and the association with postoperative outcomes.

\section{Methods \\ Study design and study population}

This prospective, observational multi-center cohort pilot study was performed at the University Medical Centre Groningen (UMCG), the Medical Center Leeuwarden (MCL), and the Medical Spectrum Twente (MST) in the Netherlands. All centers are connected via a Managed Clinical Network HPB surgery. Ethical approval was obtained from the Central Ethics Review Committee of the UMCG under registration number 201800539, and all participants provided written informed consent. The primary objective of the study was the total of activity monitor measured MVPA performed by subjects in 1 week while awaiting HPB cancer surgery. The secondary objective was (1) the association between the subject characteristics and the performed MVPA, and (2) the associations between these parameters and the surgery outcome.

The research population consisted of adult (18 years and older) patients scheduled for resection of HPB (pre)malignancy between October 2018 and September 2019. Exclusion criteria were (1) receiving an intervention aimed at influencing PA in the preoperative period. Performing health-enhancing physical activity (e.g., fitness, jogging) on own initiative was allowed since this is part of the participants normal PA behavior; (2) receiving neo-adjuvant chemo(radio)therapy during the measurement period.

Potential participants who met the inclusion criteria were identified by the responsible surgeon directly after surgery enlistment and were invited to participate immediately after being informed about their pending surgical procedure. If eligible, potential participants received instructions on the purpose of the study and were provided an information letter. After giving informed consent, participants were visited at home to perform measurements and provide the activity monitor. After surgery, participants were treated by the Enhanced Recovery After Surgery protocol as part of the care as usual.

\section{Data collection}

The primary outcome of the study was the total of activity monitor measured MVPA performed by subjects in 1 week while awaiting HPB cancer surgery. The secondary 
outcomes were (1) subject characteristics, (2) aerobic fitness, and (3) the functional recovery.

After informed consent, baseline characteristics were collected: age, height and weight, BMI (formula: weight/ height ${ }^{2}$ ), smoking behavior (yes/no), occupation (work/ volunteer, yes/no), and living (alone/together), education (lower/ higher), and alcohol consumption status. Alcohol consumption was coded as above the norm or equal to/ below norm of a maximum of one consumption per day as defined by the Dutch health council (Health Council of the Netherlands 2015). Lower education was defined as (preparatory) vocational or primary education and higher education as (preparatory) academic or higher education.

Aerobic fitness was measured directly after providing informed consent. This was measured using the Incremental Shuttle Walk Test (ISWT) to determine the influence of aerobic fitness on the PA level. As an externally paced walk test, the ISWT yields greater physiological responses in comparison with self-paced walk tests (Singh et al. 1992). The test was performed once, in accordance with the Singh protocol (Singh et al. 1992). The maximum walking distance expressed in meters and the percentage of the predicted distance based on Probst et al. were used to determine a participant's aerobic fitness level (Probst et al. 2012). Conventionally, the variability between healthy subjects is taken to be a standard deviation of $10 \%$; the normal predicted range would be from 80 to $120 \%$. Therefore, participants reaching a distance below $80 \%$ of the predicted distance were labeled unfit (Stanojevic et al. 2010).

MVPA level was measured using a hip-worn activity monitor; the Actigraph wGT3X- BT+ (Actigraph, Pensacola, FL, USA) was provided (Knaier et al. 2019; Sasaki et al. 2011; Moran et al. 2016b). The measuring period started the day after baseline characteristics were collected and lasted 7 consecutive days. Instructions for use included performing regular PA as they were used to and wearing the device during waking hours to minimize influencing sleep quality. The used cutoff counts per activity intensity level were sedentary time $(<100$ counts/ $\mathrm{min}$ ) and moderate (2020-5999 counts/min) and vigorous intensity PA ( $\geq 5999$ counts/min) with $100 \mathrm{~Hz}$ measurement epoch (Troiano et al. 2008). The total amount of MVPA is determined both as the daily median of total accumulated minutes and as the daily median minutes accumulated in at least 10-min bouts [19], where the latter is generally defined as a 10-min period with an interruption of no more than 2 min below the threshold of 2020 counts per minute [28]. MVPA measured in 10min bouts was used for further analyses. To identify non-wear time, the algorithm of Choi et al. was used (Choi et al. 2011). This algorithm defines non-wear times as periods of consecutive 0-counts for the duration of 90 min. A minimum of 6 measurement days or more had to be completed to be included in the analysis. Participants who wore the activity monitor for less than 6 days or did not undergo resection were excluded from analysis.

After completion of the activity tracker measurement week, the symptom burden of the past $24 \mathrm{~h}$ was determined by completing a translated version of the "MD Anderson Symptom Inventory" (MDASI) questionnaire. The MDASI median scores and the sub-domain "symptom burden" and "activity interference" scores were used to determine the participants' symptom burden (Cleeland et al. 2000). Median scores are used per subdomain.

After surgery, characteristic data of the surgery and outcome were collected from the electronic patient files. These included the surgery type (target organ, major/ minor surgery, open/laparoscopic surgery). Major surgery was defined as any pancreatic or liver resection of at least three liver segments (Stanojevic et al. 2010). Mortality was defined as in-hospital all-cause mortality or within 30 days after discharge. Overall complications consisted of all surgical and non-surgical complications within 30 days of surgery. Major complication was defined as any Clavien-Dindo grade $\geq$ III complication (Dindo et al. 2004).

In the post-surgery phase, functional recovery was determined as the number of days between surgery and the day that adequate pain control requiring oral analgesia only was reached without signs of active (wound) infection, tolerance of solid foods, and independent mobility sufficient to perform activities of daily living at the preoperative level (Wong-Lun-Hing et al. 2017). LOS was determined at discharge and expressed in days between surgery and hospital discharge.

\section{Statistical analyses}

Due to the pilot design of the study, the sample size target was 50 participants. This was based on comparable studies in major abdominal surgery including other organs aimed at determining preoperative PA behavior (Steffens et al. 2019). Statistical analyses were performed using the $\mathrm{R}$ software version 3.6.1 (R Development Core Team 2013). A $p$-value $\leq 0.05$ was considered significant. Continuous data were summarized by median and interquartile range (IQR) and categorical data by frequency and percentage. Range was reported if deemed relevant.

MVPA data are frequently non-normally distributed due to outlying observations for a few persons having PA levels away from the bulk of the data. Therefore, a robust regression approach was undertaken throughout this study. Robust regression is a regression method suitable for non-normally distributed data with outliers; this method prevents a large influence on the association 
coefficients by outlying observations (Yohai et al. 1991; Koller and Stabel 2011; Hubert and Rousseeuw 1997). All enlisted patients, recording 6 or more measurement days, were used in the MVPA analyses; participants only receiving an exploratory laparotomy or laparoscopy without resection and those who were eventually not operated upon were excluded from the complication's analyses. Furthermore, all participants that reached discharge from hospital were included in the time to FR analysis.

The association between the level of MVPA in 10-min bouts and the preoperative variables, and time to FR and pre- and perioperative variables was determined by univariate and multivariable robust regression (Portney and Watkins 2009). Furthermore, univariate and multivariable robust logistic regression was used to determine the odds ratio (OR) of the occurrence of complications based on the preoperative and per-operative variables (Koller and Stabel 2011; Hubert and Rousseeuw 1997; Portney and Watkins 2009). All multivariable analyses were performed using the measured independent explanatory variables identified to potentially have a significant association with the dependent variable from univariate regression analysis. Lastly, a subset analysis was performed to determine the association between MVPA in 10-min bouts and time to FR within the major complications group via univariate robust regression. LOS analysis is reported in the supplementary material.

\section{Results}

A total of 154 patients who met the inclusion criteria were approached for participation; 40 patients (26\%) consented to participate in the study. Two participants were excluded from PA analysis due to not meeting wear-time criteria; the measurements from the remaining 38 participants were used for further analysis. Five participants had either no surgery procedure (one participant) or received a procedure without resection (exploratory laparotomy only, four participants). These patients were excluded from complication analyses. Furthermore, two participants were excluded from the time to FR analyses due to postoperative mortality. Figure 1 displays the flowchart of participant inclusion. Median time between placement on surgery awaiting list until

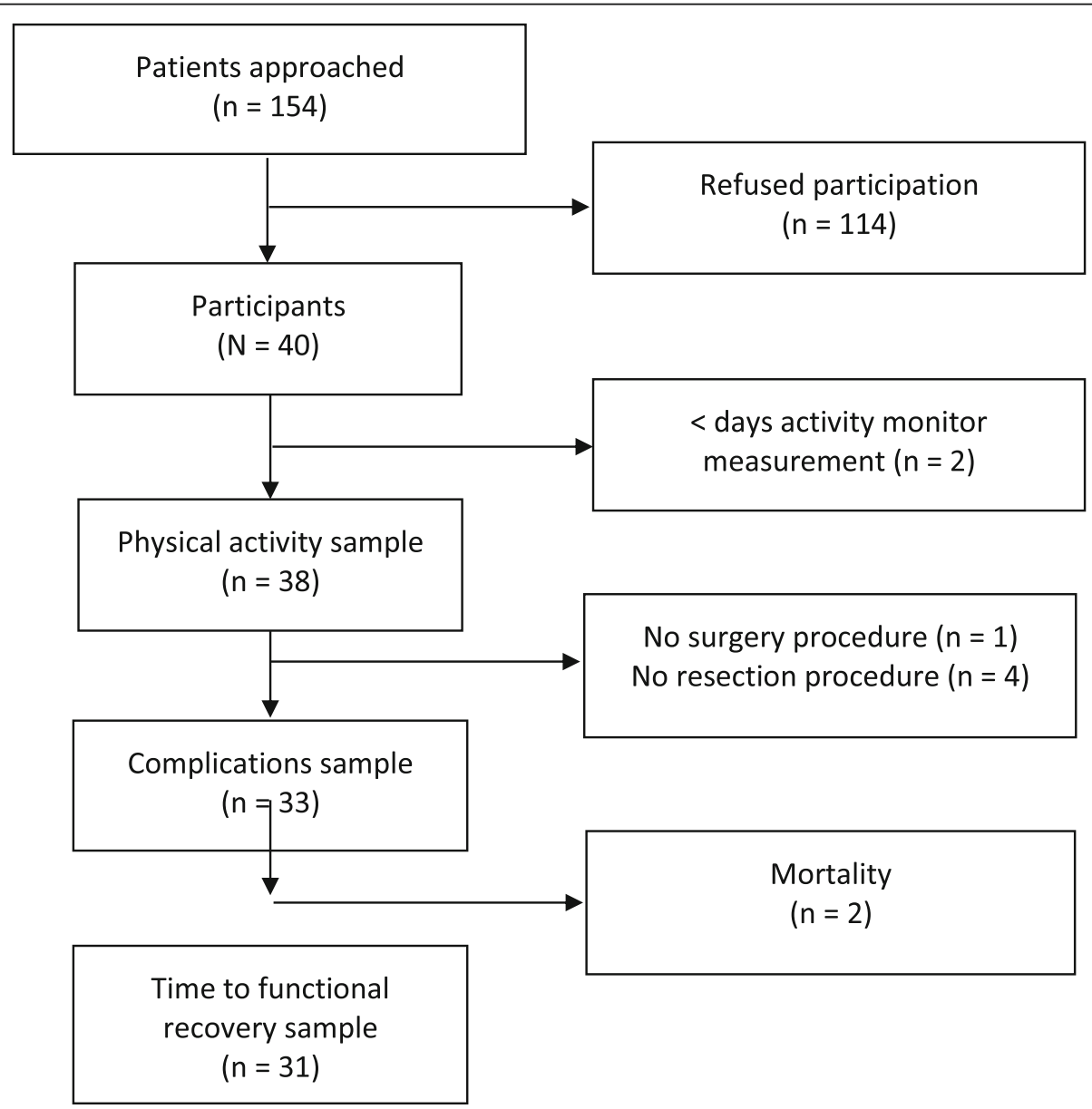

Fig. 1 Inclusion flowchart 
baseline measurements and between baseline measurements, including the start of the activity monitor period, until surgery day was 0 days (IQR $0-0.75$, range $0-14$ ) and 31.5 days (IQR $22.25-45$, range 9-171) respectively.

\section{Characteristics}

Of the 38 participants, 22 participants were male, and the mean age of participants in both the PA and surgery outcome group was 65.8 years $( \pm 9.4)$ and 65.5 years $( \pm$ $9.8)$, respectively. The label unfit was given to 22 participants, with a median $69 \%( \pm 31 \%)$ distance covered of the predicted ISWT distance in the PA group and 65\% $( \pm 28 \%)$ in the surgery outcome group. Of the 33 participants that underwent the surgery procedure, 10 developed major complications. Participant characteristics and perioperative data are presented in Table 1 .

\section{Physical activity}

The participants' median level of MVPA was $10.7 \mathrm{~min}$ per day, wearing the activity monitor $66 \%( \pm 29 \%)$ of waking hours per day. The MVPA variability between participants was large, ranging from 0 to $60.1 \mathrm{~min}$ per day. Eight participants $(21 \%)$ met the PA guideline of 150 min MVPA per week. The level of MVPA reduced with 0.52 min per advancing age year, $\left(R^{2}=.31, p=.001\right)$, and increased by $.02 \mathrm{~min}$ per $\mathrm{m}$ covered during the ISWT $\left(R^{2}=.35, p=.008\right)$, and subjects labeled as fit (7.90 min more in fit subjects, $R^{2}=.20, p=.023$ ) were identified as correlating with MVPA via univariate robust regression. Since the aerobic fitness level was derived from the ISWT distance covered, this variable was omitted from multivariable regression. The multivariable regression model for performed MVPA determined by multivariable robust regression was $29.05+$ (ISWT (meters) * 0.01) + (age (years)* -0.35) (adj. $\left.R^{2}=.41\right)$. The association between MVPA and preoperative variables via univariate and multivariable robust regression is displayed in Table 2.

\section{Complications}

Seventeen participants (51\%) had complications of which ten (30\%) were major. The association found between MVPA and the presence of major complications (OR = $0.99,95 \% \mathrm{CI}=0.95-1.04, p=.703$ ) was not statistically significant. A statistically significant association was found between the presence of major complications and BMI $(\mathrm{OR}=.71,95 \% \mathrm{CI}=0.52-0.98, p=.036)$, \% of predicted ISWT (OR $=.98,95 \%$ CI $.97-.99, p=.008)$, and surgery type $(\mathrm{OR}=.24,95 \% \mathrm{CI}=0.06-0.95, p=.043)$. The odds of major complications decrease with increasing BMI, more distance covered on the ISWT compared to the predicted distance, and a minor surgery procedure. The OR from multivariable robust logistic regression including surgery type and ISWT (\% of predicted) was found to be (surgery type ${ }^{(\text {minor }) * 0.144)}+$ (ISWT $(\%$ of predicted) * 0.948). The OR from robust univariate and multivariable logistic regression for the occurrence of major complications is displayed in Table 3.

\section{Time to functional recovery}

The median time to FR was 8 (IQR 5-12) days, ranging from 2 till 56 days. Higher MVPA in both total accumulated bouts $(-0.07$ less days per minute increase, $p=.009)$ and 10-min bouts $(-0.14$ less days per minute increase, $p=$ $.007)$, a minor surgery procedure ( -6.39 less days, $p \leq .001)$, and a higher BMI $\left(-0.46\right.$ less days per $\mathrm{kg} / \mathrm{cm}^{2}$ increase, $p=$ .006) resulted in less time to FR. The multivariable model yields an adj. $R^{2} .43$; the model is as follows $12.54+$ (MVPA $\left.{ }^{\text {(minutes) } *}-.08\right)+$ (surgery size ${ }^{(1 \text { if minor, } 0 \text { if major) * }}$ -5.64). The association between MVPA in 10-min bouts and time to FR in the subset where major complications occurred was -0.352 less days to FR per minute increase $\left(R^{2}=.460, p=.023\right)$. Time to $\mathrm{FR}$ analysis is displayed in Table 4.

\section{Discussion}

To our knowledge, this is the first study investigating device-measured MVPA levels in HPB resection candidates not receiving PA interventions. Patients scheduled for HPB surgery engage in low daily MVPA at baseline while waiting for surgery. Furthermore, a relation was found between the level of MVPA and time to FR after $\mathrm{HPB}$ surgery for (pre)malignancy; patients with higher levels of PA require less time to FR. The current findings suggest that increasing a patient's preoperative MVPA level might be an intervention to improve the postsurgical outcome.

\section{Physical activity}

The median MVPA level measured in the current study was low but comparable to other preoperative activity monitor measured MVPA studies, e.g., gastric bypass and lumbar fusion surgery (Van der Meij et al. 2017; Lotzke et al. 2018). However, this comparison is somewhat arbitrary due to the influence of age and the variety in symptom burden experienced among different pathologies. Furthermore, the variety in activity monitor device configuration like MVPA cutoff point and weartime validation highly influences the results (Gorman et al. 2014). Nevertheless, this study demonstrates that the majority $(79 \%)$ of the patients enlisted for HPB surgery did not perform sufficient MVPA to meet the guideline of $150 \mathrm{~min}$ MVPA per week (Weggemans et al. 2018; WHO 2009).

These findings might be explained by the psychological impact of being enlisted for surgery because of malignancy. Namely, being informed about the presence of a tumor can result in changes in PA behavior 
Table 1 Patient characteristics

\begin{tabular}{|c|c|c|}
\hline Variable & $\begin{array}{l}\text { Physical activity sample }(N=38) \\
N(\%) \text { or median (IQR) }\end{array}$ & $\begin{array}{l}\text { Surgery outcome sample ( } N=33) \\
N(\%) \text { or median (IQR) }\end{array}$ \\
\hline \multicolumn{3}{|l|}{ Gender } \\
\hline Female & $16(42 \%)$ & $14(42 \%)$ \\
\hline Male & $22(58 \%)$ & 19 (58\%) \\
\hline Age (years) & $66(58.25-74.75)$ & $66(56-74)$ \\
\hline Height $(\mathrm{cm})$ & $173(167.8-182.8)$ & $173(167-182)$ \\
\hline Weight $(\mathrm{kg})$ & $77(70.1-87.6)$ & $77(70.5-88)$ \\
\hline BMI $\left(\mathrm{kg} / \mathrm{cm}^{2}\right)$ & $24.9(22.8-28.2)$ & $24.8(22.7-28.3)$ \\
\hline \multicolumn{3}{|l|}{ Living situation } \\
\hline Living alone & $8(21 \%)$ & $7(21 \%)$ \\
\hline Living together & $30(79 \%)$ & $26(79 \%)$ \\
\hline \multicolumn{3}{|l|}{ Educational level } \\
\hline Lower education & $23(61 \%)$ & 19 (58\%) \\
\hline Higher education & 15 (39\%) & $14(42 \%)$ \\
\hline \multicolumn{3}{|l|}{ Work } \\
\hline Employed & $14(37 \%)$ & $12(36 \%)$ \\
\hline Unemployed & $24(63 \%)$ & $21(64 \%)$ \\
\hline \multicolumn{3}{|l|}{ Alcohol consumption } \\
\hline Above norm & $10(26 \%)$ & $9(27 \%)$ \\
\hline Equal or below norm & $28(74 \%)$ & $24(73 \%)$ \\
\hline \multicolumn{3}{|l|}{ Smoking } \\
\hline Yes & $5(13 \%)$ & $5(15 \%)$ \\
\hline No & $33(87 \%)$ & $28(85 \%)$ \\
\hline MDASI total (sum score) & $1.87( \pm 1.75)(N=32)$ & $1.86( \pm 1.85)(N=28)$ \\
\hline Symptoms & $1.81( \pm 1.68)(N=32)$ & $1.84( \pm 1.81)(N=28)$ \\
\hline Activity & $1.91( \pm 2.29)(N=32)$ & $1.92( \pm 2.30)(N=28)$ \\
\hline ISWT (m) & $430(310-473.1)$ & $430(280-620)$ \\
\hline Percentage of predicted (\%) & $69( \pm 31)$ & $65( \pm 28)$ \\
\hline Labeled fit/unfit & $16 / 22(42 \% / 58 \%)$ & $14 / 19(42 \% / 58 \%)$ \\
\hline \multicolumn{3}{|l|}{ Physical activity (min) } \\
\hline Time spend sedentary (per day) & $564.45(310.4-662.4)$ & $580.4(417.0-668.3)$ \\
\hline Time spend sedentary (per week) & $3951.1(2172.8-4636.6)$ & $4062.8(2918.9-4678.5)$ \\
\hline MVPA (total accumulated per day) & $26.4(16.8-43.8)$ & $24.4(16.6-34.5)$ \\
\hline MVPA (total accumulated per week) & $184.8(117.7-306.9)$ & $170.6(116.1-241.2)$ \\
\hline Adherence to guideline (yes/no) ${ }^{a}$ & $21 / 17(55 \% / 45 \%)$ & $17 / 16(48 \% / 52 \%)$ \\
\hline MVPA (total 10-min bouts per day) & $10.7(6.9-18.0)$ & $11.6(7.5-21.3)$ \\
\hline MVPA (total 10-min bouts per week) & $74.7(48.3-125.94)$ & $81(52.6-148.9)$ \\
\hline Adherence to guideline (yes/no) ${ }^{b}$ & $8 / 30(21 \% / 79 \%)$ & $8 / 25(24 \% / 76 \%)$ \\
\hline Wear time in percentage & $66 \%( \pm 27.6)$ & $69.2 \%( \pm 26.7)$ \\
\hline \multicolumn{3}{|l|}{ Highest Clavien-Dindo rating } \\
\hline No complication & & $16(49 \%)$ \\
\hline Minor/major & & $7 / 10(21 \% / 30 \%)$ \\
\hline Grade I & & $2(6 \%)$ \\
\hline Grade II & & $5(15 \%)$ \\
\hline
\end{tabular}


Table 1 Patient characteristics (Continued)

\begin{tabular}{|c|c|c|}
\hline Variable & $\begin{array}{l}\text { Physical activity sample }(N=38) \\
N(\%) \text { or median (IQR) }\end{array}$ & $\begin{array}{l}\text { Surgery outcome sample }(N=33) \\
N(\%) \text { or median (IQR) }\end{array}$ \\
\hline Grade IIla & & $3(9 \%)$ \\
\hline Grade IIIb & & $5(15 \%)$ \\
\hline Grade IV & & $0(0 \%)$ \\
\hline Grade V & & $2(6 \%)$ \\
\hline \multicolumn{3}{|l|}{ Target organ } \\
\hline Pancreas & & $13(39 \%)$ \\
\hline Liver & & $20(61 \%)$ \\
\hline \multicolumn{3}{|l|}{ Type of procedure } \\
\hline Open & & $24(72 \%)$ \\
\hline Laparoscopic & & $9(28 \%)$ \\
\hline \multicolumn{3}{|l|}{ Procedure size } \\
\hline Major & & $18(54 \%)$ \\
\hline Minor & & $15(46 \%)$ \\
\hline Length of hospital stay (days) & & $9(7-15)$ \\
\hline Time to functional recovery (days) & & $8(5-12)$ \\
\hline Mortality & & $2(6 \%)$ \\
\hline
\end{tabular}

BMI Body mass index, MDASI MD Anderson Symptom Inventory, ISWT Incremental Shuttle Walk Test, PA Physical activity, MVPA Moderate to vigorous physical activity, avg. Average

${ }^{a} 150$ min per week accumulated total bouts

${ }^{\mathrm{b}} 150$ min per week accumulated 10 -min bouts

Table 2 Uni- and multivariate robust regression association between preoperative variables and moderate to vigorous physical activity (10-min bouts)

\begin{tabular}{|c|c|c|c|c|c|c|}
\hline Variable & Estimate & Std. error & $R^{2}$ & $t$-value & $p$-value & Adj. $R^{2}$ \\
\hline Gender (female) & -2.140 & 2.867 & 0.016 & -0.746 & .460 & \\
\hline Age (years) & -0.521 & 0.146 & 0.309 & -3.565 & $.001 *$ & \\
\hline BMI $\left(\mathrm{kg} / \mathrm{cm}^{2}\right)$ & 0.358 & 0.642 & 0.0332 & 0.557 & .581 & \\
\hline Living situation (together) & -0.999 & 4.335 & 0.002 & -0.230 & .819 & \\
\hline Work status (employed) & 5.491 & 3.686 & 0.092 & 1.490 & .145 & \\
\hline Education (high) & 5.045 & 3.153 & 0.083 & 1.600 & .118 & \\
\hline Smoking status (no) & 1.263 & 2.771 & 0.002 & 0.456 & .651 & \\
\hline Alcohol norm (above) & 5.935 & 3.415 & 0.101 & 1.738 & .091 & \\
\hline MDASI total (avg, $n=32$ ) & -1.058 & 0.848 & 0.045 & -1.247 & .222 & \\
\hline MDASI symptoms (avg, $n=32$ ) & -0.884 & 0.823 & 0.031 & -1.074 & .291 & \\
\hline MDASI activities (avg, $n=32$ ) & -0.865 & 0.579 & 0.050 & -1.496 & .145 & \\
\hline ISWT (m) & 0.020 & 0.007 & 0.346 & 2.796 & $.008^{*}$ & \\
\hline ISWT (\% of predicted) & 0.091 & 0.050 & 0.112 & 1.811 & .078 & \\
\hline Aerobic fitness (labeled fit) & 7.905 & 3.325 & 0.204 & 2.378 & $.023^{*}$ & \\
\hline \multicolumn{7}{|l|}{ Multivariate } \\
\hline Constant & 29.048 & 11.107 & & 2.615 & $.013^{*}$ & .414 \\
\hline Age (years) & -0.348 & 0.135 & & -2.576 & $.014^{*}$ & \\
\hline ISWT (m) & 0.013 & 0.006 & & 2.238 & $.031^{*}$ & \\
\hline
\end{tabular}

BMI Body mass index, ISWT Incremental Shuttle Walk Test, MDASI MD Anderson Symptom Inventory, avg. Average ${ }^{*} p \leq .05$ 
Table 3 Uni- and multivariate logistic robust regression association between pre- and perioperative variables and complications Clavien-Dindo grade $\geq 11 \mid$

\begin{tabular}{|c|c|c|c|}
\hline Variable & OR & $95 \% \mathrm{Cl}$ & $p$-value \\
\hline Gender (female) & 0.952 & $\mathbf{0 . 2 2 6 - 4 . 0 0 6}$ & .947 \\
\hline Age (years) & 1.017 & $0.944-1.096$ & .650 \\
\hline BMI $\left(\mathrm{kg} / \mathrm{cm}^{2}\right)$ & 0.714 & $0.521-0.979$ & $.036^{*}$ \\
\hline Living situation (living together) & 0.706 & $0.129-3.868$ & .688 \\
\hline Working status (works) & 1.250 & $0.507-3.081$ & .627 \\
\hline Education level (high) & 1.900 & $0.759-4.759$ & .171 \\
\hline Alcohol consumption (above norm) & 0.533 & $0.142-1.996$ & .351 \\
\hline Smoking status (no) & 0.893 & $0.273-2.914$ & .851 \\
\hline MDASI total (avg, $n=28$ ) & 0.980 & $0.728-1.319$ & .893 \\
\hline MDASI symptom (avg, $n=28$ ) & 0.937 & $0.680-1.290$ & .688 \\
\hline MDASI activity (avg, $n=28$ ) & 1.016 & $0.827-1.249$ & .879 \\
\hline ISWT (m) & 0.998 & $0.996-1.001$ & .066 \\
\hline ISWT (\% of predicted) & 0.981 & $0.967-0.995$ & $.008^{*}$ \\
\hline Aerobic fitness norm (labeled fit) & 0.875 & $0.332-2.304$ & .787 \\
\hline Time spend sedentary (min) & 0.999 & $0.997-1.001$ & .321 \\
\hline Daily MVPA —-total accumulated (min) & 0.996 & $0.976-1.017$ & .745 \\
\hline Daily MVPA-10-min bouts (min) & 0.991 & $0.949-1.036$ & .703 \\
\hline Laparoscopic/closed surgery (laparoscopic) & 0.242 & $0.034-1.720$ & .156 \\
\hline Major/minor surgery (minor) & 0.240 & $0.060-0.953$ & $.043^{*}$ \\
\hline \multicolumn{4}{|l|}{ Multivariate } \\
\hline Major/minor surgery (minor) & 0.144 & $0.024-0.858$ & $.033^{*}$ \\
\hline ISWT (\% of predicted) & 0.984 & $0.954-1.015$ & .309 \\
\hline
\end{tabular}

OR Odds ratio, 95\% CI 95\% confidence interval, BMI Body mass index, avg. Average, ISWT Incremental Shuttle Walk Test, MDASI MD Anderson Symptom Inventory, MVPA Moderate to vigorous physical activity

$* p \leq .05$

(Allender et al. 2008). Participants were recruited directly after being enlisted, and measurements were performed during the first week after enlistment. Due to the design of the study, it remains unclear whether the measured level of MVPA and performed distance covered on the ISWT is temporary. These values might reach higher levels once the impact of the news diminishes. Previous studies have reported an increase in PA during the waiting period (Kim et al. 2009). The observed increase might have been caused by an increased awareness or social desirability of the participant, as they had to fill out PA questionnaires, wear a PA monitor, or perform physical fitness measures during this study. Furthermore, it seems likely that patients perform less MVPA due to the interference of tumor-related symptoms. However, there was no evidence for an association between the experienced symptom burden like pain and fatigue, measured with the MDASI, and the level of performed MVPA. Notably, participants experienced fairly low symptom interference in our study, 1.87 points on mean out of 10. It therefore seems probable that subjects with high symptom interference were more likely to reject study participation. Due to the small sample size, no subcategory analysis with subjects experiencing high levels of symptom burden could be performed.

\section{Postoperative outcomes}

A significant association was found between MVPA and time to FR $\left(R^{2}=0.17, p=.006\right)$ but no significant association was found between MVPA and the occurrence of postoperative complications $(\mathrm{OR}=0.99,95 \% \mathrm{CI}=0.95$ 1.03, $p=.67$ ). These findings are in accordance with the systematic review and meta-analysis in preoperative cancer patients by Steffens et al., who found an association between higher levels of preoperative MVPA and a shorter absolute $\mathrm{LOS}(\mathrm{OR}=3.66 ; 95 \% \mathrm{CI}=1.38$ to 9.6), but not with postoperative complications $(\mathrm{OR}=2.60$; $95 \%$ $\mathrm{CI}=0.59$ to 11.37$)$. The majority of studies in this metaanalysis used self-reported MVPA and participants undergoing neo-adjuvant (physical) therapy (Steffens et al. 2019). However, the meta-analysis as well as the current study consistently indicates that higher levels of MVPA positively influence a patient's capacity to endure the demands of surgery (Steffens et al. 2019). 
Table 4 Uni- and multivariate robust regression association with time to functional recovery

\begin{tabular}{|c|c|c|c|c|c|c|}
\hline Variable & Estimate & Std. error & $R^{2}$ & $t$-value & $p$-value & Adj. $R^{2}$ \\
\hline Gender (female) & 0.754 & 2.206 & 0.006 & 0.342 & .735 & \\
\hline Age (years) & 0.140 & 0.097 & 0.097 & 1.449 & .158 & \\
\hline BMI $\left(\mathrm{kg} / \mathrm{cm}^{2}\right)$ & -0.463 & 0.156 & 0.206 & -2.974 & $.006^{*}$ & \\
\hline Living situation (together) & 0.902 & 1.979 & 0.005 & 0.456 & .652 & \\
\hline Working status (employed) & -0.655 & 1.903 & 0.004 & -0.344 & .733 & \\
\hline Education level (high) & 0.365 & 2.343 & 0.001 & 0.156 & .877 & \\
\hline Alcohol norm (above) & -1.255 & 2.061 & 0.014 & -0.609 & .547 & \\
\hline Smoking status (no) & 2.942 & 2.882 & 0.044 & 1.021 & .316 & \\
\hline MDASI total (avg., $n=27$ ) & 0.269 & 0.390 & 0.011 & 0.691 & .496 & \\
\hline MDASI symptoms (avg, $n=27$ ) & 0.166 & 0.399 & 0.004 & 0.417 & 680 & \\
\hline MDASI activities (avg, $n=27$ ) & 0.425 & 0.379 & 0.031 & 1.124 & .272 & \\
\hline ISWT (m) & -0.007 & 0.004 & 0.098 & -1.679 & .104 & \\
\hline ISWT (\% of predicted) & -0.054 & 0.036 & 0.076 & -1.508 & .142 & \\
\hline Aerobic fitness norm (labeled fit) & -2.172 & 1.862 & 0.044 & -1.167 & .253 & \\
\hline Time spend sedentary (min) & -0.006 & 0.004 & 0.056 & -1.345 & .189 & \\
\hline Daily MVPA—total accumulated (min) & -0.068 & 0.024 & 0.157 & -2.793 & $.009^{*}$ & \\
\hline Daily MVPA-10-min bouts (min) & -0.145 & 0.050 & 0.174 & -2.905 & $.007^{*}$ & \\
\hline Laparoscopic/open surgery (laparoscopic) & -1.555 & 2.045 & 0.021 & -0.761 & .453 & \\
\hline Major/minor surgery (minor) & -6.392 & 1.638 & 0.426 & -3.902 & $<.001^{*}$ & \\
\hline \multicolumn{7}{|l|}{ Multivariate } \\
\hline Constant & 12.545 & 2.062 & & 6.083 & $<.001^{*}$ & .432 \\
\hline Major/minor surgery (minor) & -5.643 & 1.803 & & -3.130 & $.004^{*}$ & \\
\hline Daily MVPA-10-min bouts (min) & -0.079 & 0.031 & & -2.573 & $.016^{*}$ & \\
\hline \multicolumn{7}{|l|}{ Major complications subset analysis } \\
\hline Daily MVPA - 10-minute bouts (min) & -0.352 & 0.126 & 0.460 & -2.798 & $.023^{*}$ & \\
\hline
\end{tabular}

$B M I$ body mass index, ISWT Incremental Shuttle Walk Test, MDASI MD Anderson Symptom Inventory, MVPA moderate to vigorous physical activity ${ }^{*} p \leq .05$

A subject's level of preoperative MVPA was associated with reduced time to FR; $43 \%$ of the time variance to FR could be explained via multivariable robust regression including surgery size and MVPA levels. This reduction might be explained by the lower relative capacity needed to perform activities in daily living by patients with higher levels of aerobic fitness. FR is determined by both functional and physiological criteria, that is, higher levels of aerobic fitness increase a patient's functional capacity to perform activities of daily living (Jackson et al. 2009). However, caution is needed when interpreting these results since we did not directly measure aerobic reserves at the moment of FR.

Furthermore, a higher percentage of predicted distance covered on the ISWT was associated with reduced OR for the occurrence of major postoperative complications found by univariate robust regression. Similar reductions have been reported in multiple studies among a large variety of surgical procedures (Kumar and Garcea 2018; Snowden et al. 2010; Simões et al. 2018; Van Beijsterveld et al. 2019; Levett and Grocott 2015). These reductions might be explained by the higher aerobic reserves enhancing the body's capacity to cope with the responses to the surgical procedure. Nevertheless, a higher percentage of predicted distance covered on the ISWT was not found to have a significant association in multivariable robust regression including surgery size. Notably, the current study found lower OR for the occurrence of major complications in subjects with a higher BMI. This result is inconsistent to previous studies showing increased OR for the development of major complications in obese and overweight subjects undergoing pancreatectomy procedures (Lovasik et al. 2019). This difference might be explained by the overrepresentation of subjects with high BMI scores undergoing a major surgery procedure in the present study (Wilcoxon rank sum test, $W$ $=74, p=.02$ ). Major surgery has a higher risk of resulting in major complications. Therefore, BMI was removed from multivariable regression analysis in the current study. Additionally, we found a reduction in 
time to FR after major complications in subjects performing higher levels of PA. Therefore, it could be concluded that because subjects with a higher level of MVPA have more capacity to cope with the demands endured by complications, the impact of complications is less. Nevertheless, these results should be interpreted with some caution since only nine subjects reached FR after major complications.

\section{Treatment opportunity}

This study identifies preoperative MVPA as a modifiable patient factor to reduce time to FR. Multiple associations between performed MVPA and preoperative variables were found, namely, MVPA decreased with advancing age with $0.52 \mathrm{~min}$ per age year $(p \leq .001)$ and increased in participants with higher aerobic fitness, covering more distance during the ISWT (0.02 min per $\mathrm{m}, p=.008)$. Since both PA and aerobic fitness decline with age (Milanović et al. 2013), these findings underpin the hypothesis that unfit and older patients could benefit most from interventions aimed to improve aerobic fitness and to increase MVPA levels, especially in the waiting time before surgery. Furthermore, although this study does not include a detailed cost analysis, increasing the level of preoperative MVPA via relative low-cost treatment modalities as education, wearables, and physiotherapy may be of particular relevance for the reduction of hospital costs due to the shorter hospital stay (see supplementary data) (Straatman et al. 2015).

\section{Limitations}

There are some limitations to this observational pilot study. The first is that no pre-trail sample-size calculation was performed. This can impact the results with a higher risk of type II errors. Since a limited number of HPB resections are yearly performed, participants were included via convenience sampling in a multi-center design. However, the final sample size obtained is comparable with several other studies aimed at measuring PA via activity monitor devices in major abdominal surgery (Mungovan et al. 2013; Dronkers et al. 2013). Unfortunately, only $26 \%$ of the approached subjects provided consent to participate in the study. A reason for this low participation rate might have been the moment of inclusion, namely, directly after being enlisted for surgery. Frequently mentioned reasons for declining participation were the feeling of being emotionally overwhelmed and currently not having the energy to endorse participation. These reasons might have induced a sample slightly biased in the direction of somewhat fitter patients. Larger sample sizes and less strenuous PA measurements can be more easily acquired via questionnaires. Nevertheless, activity monitor measured PA is a feasible and more reliable method of determining PA and is therefore recommended (Steffens et al. 2019; Van der Meij et al. 2017).

\section{Conclusion}

This study demonstrates that $79 \%$ of the patients enlisted for resection of HPB (pre) malignancy performed insufficient MVPA. A higher level of MVPA, objectively measured with an activity monitor, was independently associated with a shorter time to FR. However, levels of MVPA were not associated with postoperative complications. Stimulating MVPA in the waiting time for surgery might help to reduce the LOS. These findings add to a growing body of evidence suggesting that higher levels of MVPA positively influence a patient's capacity to endure the demands of surgery and improve the outcome of surgery.

\section{Abbreviations}

MVPA: Moderate to vigorous physical activity; PA: Physical activity; HPB: Hepato-pancreato-biliary; LOS: Length of hospital stay; FR: Functional recovery; ISWT: Incremental Shuttle Walk Test; MDASI: MD Anderson

Symptom Inventory; BMI: Body mass index; OR: Odds ratio; IQR: Interquartile range

\section{Supplementary Information}

The online version contains supplementary material available at https://doi. org/10.1186/s13741-021-00202-7.

Additional file 1: Supplementary table. Uni- and multivariate robust regression association with absolute length of hospital stay.

\section{Acknowledgements}

The authors would like to acknowledge the invaluable contribution of the research nurses at the University Medical Hospital Groningen, Medical Centre Leeuwarden, the Medical Spectrum Twente, Rebekka van der Laan, Haike Verbree, and Sander Koops.

\section{Authors' contributions}

CM carried out the design of the study, data gathering, and statistical analysis and drafted the manuscript. WK helped to perform and design statistical analysis and draft of the manuscript. TT helped to design the study and draft the manuscript. DL helped in data gathering and draft of the manuscript. HE helped in data gathering and draft of the manuscript. CvdS helped in the design of the study and the draft of the manuscript. JK helped in the design of the study, data gathering, and in the draft of the manuscript. The authors read and approved the final manuscript.

\section{Funding}

The study was supported by the University Medical Centre Groningen, the Netherlands; Utrecht University, the Netherlands; and the Hanze University of Applied Sciences Groningen, the Netherlands.

\section{Availability of data and materials}

The datasets used and analyzed during the current study are available from the corresponding author on reasonable request.

\section{Declarations}

Ethics approval and consent to participate

Ethical approval was obtained from the Central Ethics Review Committee of the UMCG under registration number 201800539, and all participants provided written informed consent. 


\section{Consent for publication}

All authors have read the manuscript, have approved the paper, and agreed to it being submitted for publication.

\section{Competing interests}

The authors declare that they have no competing interests.

\begin{abstract}
Author details
${ }^{1}$ Research Group Healthy Ageing, Allied Health Care and Nursing, Hanze University of Applied Sciences, Petrus Driessenstraat 3, 9714 CA Groningen, The Netherlands. ${ }^{2}$ Child Development and Exercise Center, University Medical Center Utrecht, Utrecht, The Netherlands. ${ }^{3}$ Department of Surgery, Medical Spectrum Twente, Enschede, The Netherlands. ${ }^{4}$ Department of Surgery, Medical Centre Leeuwarden, Leeuwarden, The Netherlands. ${ }^{5}$ Department of Rehabilitation Medicine, University Medical Center Groningen, University of Groningen, Groningen, The Netherlands. ${ }^{6}$ Health Psychology Research, University Medical Center Groningen, University of Groningen, Groningen, The Netherlands. ${ }^{7}$ Department of Hepatobiliary Surgery and Liver Transplantation, University Medical Centre Groningen, Groningen, The Netherlands.
\end{abstract}

Received: 20 October 2020 Accepted: 16 June 2021

Published online: 04 October 2021

\section{References}

Allender S, Hutchinson L, Foster C. Life-change events and participation in physical activity: a systematic review. Health Promot Int. 2008;23(2):160-72.

Bray F, Ferlay J, Soerjomataram I, Siegel RL, Torre LA, Jemal A. Global cancer statistics 2018: GLOBOCAN estimates of incidence and mortality worldwide for 36 cancers in 185 countries. CA Cancer J Clin. 2018;68(6):394-424.

Chandrabalan W, McMillan DC, Carter R, Kinsella J, McKay CJ, Carter CR, et al. Preoperative cardiopulmonary exercise testing predicts adverse post-operative events and non-progression to adjuvant therapy after major pancreatic surgery. HPB. 2013;15(11):899-907.

Chastin SFM, De Craemer M, De Cocker K, Powell L, Van Cauwenberg J, Dall P, et al. How does light-intensity physical activity associate with adult cardiometabolic health and mortality? Systematic review with meta-analysis of experimental and observational studies. BJ Sports. 2019;53:370-6.

Choi L, Liu Z, Matthews CE, Buchowski MS. Validation of accelerometer wear and nonwear time. Med Sci Sport Exerc. 2011:43(2):357-64.

Cleeland CS, Mendoza TR, Wang XS, Chou C, Harle MT, Morrissey M, et al. Assessing symptom distress in cancer patients: the M.D. Anderson Symptom Inventory. Cancer. 2000;89(7):1634-46 Available from: http://www.ncbi.nlm. nih.gov/pubmed/11013380.

Colley RC, Butler G, Garriguet D, Prince SA, Roberts KC. Comparison of selfreported and accelerometer-measured physical activity among Canadian youth. Heal Reports. 2019:30(7):3-12.

Dindo D, Demartines N, Clavien PA. Classification of surgical complications: a new proposal with evaluation in a cohort of 6336 patients and results of a survey. Ann Surg. 2004;240(2):205-13.

Dronkers JJ, Chorus AMJ, Van Meeteren NLU, Hopman-Rock M. The association of pre-operative physical fitness and physical activity with outcome after scheduled major abdominal surgery. Anaesthesia. 2013;68(1):67-73.

Ferlay J, Colombet M, Soerjomataram I, Dyba T, Randi G, Bettio M, et al. Cancer incidence and mortality patterns in Europe: estimates for 40 countries and 25 major cancers in 2018. Eur J Cancer. 2018;103:356-87. Available from. https://doi.org/10.1016/j.ejca.2018.07.005.

Gorman E, Hanson HM, Yang PH, Khan KM, Liu-Ambrose T, Ashe MC. Accelerometry analysis of physical activity and sedentary behavior in older adults: a systematic review and data analysis. Eur Rev Aging Phys Act. 2014; 11(1):35-49.

Hallal PC, Andersen LB, Bull FC, Guthold R, Haskell W, Ekelund U, et al. Global physical activity levels: surveillance progress, pitfalls, and prospects. Lancet. 2012;380(9838):247-57. Available from. https://doi.org/10.1016/S0140-6736(12 60646-1.

Health Council of the Netherlands. Richtlijnen goede voeding 2015. Gezondheidsraad. 2015;24:1-95 Available from: https://www.gezondheidsraa d.nl/sites/default/files/201524_richtlijnen_goede_voeding_2015.pdf.

Hubert M, Rousseeuw PJ. Robust regression with both continuous and binary regressors. J Stat Plan Inference. 1997;57(1):153-63.
Jackson AS, Sui X, Hébert JR, Church TS, Blair SN. Role of lifestyle and aging on the longitudinal change in cardiorespiratory fitness. Arch Intern Med. 2009; 169(19):1781-7.

Kim DJ, Mayo NE, Carli F, Montgomery DL, Zavorsky GS. Responsive measures to prehabilitation in patients undergoing bowel resection surgery. Tohoku J Exp Med. 2009;217(2):109-15.

Knaier R, Höchsmann C, Infanger D, Hinrichs T, Schmidt-Trucksäss A. Validation of automatic wear-time detection algorithms in a free-living setting of wristworn and hip-worn ActiGraph GT3X+. BMC Public Health. 2019;19(1):1-6.

Koller M, Stabel W. Sharpening Wald-type inference in robust regression for small samples. Comput Stat Data Anal. 2011;55(8):2504-25115.

Kommalapati A, Tella SH, Goyal G, Ma WW, Mahipal A. Contemporary management of localized resectable pancreatic cancer. Cancers (Basel). 2018; 10(1):1-15.

Kontis V, Bennett JE, Mathers CD, Li G, Foreman K, Ezzati M. Future life expectancy in 35 industrialised countries: projections with a Bayesian model ensemble. Lancet. 2017;389(10076):1323-35. Available from. https://doi.org/1 0.1016/50140-6736(16)32381-9.

Kumar R, Garcea G. Cardiopulmonary exercise testing in hepato-biliary \& pancreas cancer surgery - a systematic review: are we any further than walking up a flight of stairs? Int J Surg. 2018;52:201-7. Available from. https://doi.org/10.1 016/j.jijsu.2018.02.019.

Levett DZH, Grocott MPW. Cardiopulmonary exercise testing, prehabilitation, and Enhanced Recovery After Surgery (ERAS). Can J Anaesth. 2015;62(2):131-42.

Lotzke $\mathrm{H}$, Jakobsson M, Gutke A, Hagströmer M, Brisby H, Hägg O, et al. Patients with severe low back pain exhibit a low level of physical activity before lumbar fusion surgery: a cross-sectional study. BMC Musculoskelet Disord. 2018;19(1):1-9.

Lovasik BP, Kron P, Clavien PA, Petrowsky H, Kooby DA. Pancreatectomy and body mass index: an international evaluation of cumulative postoperative complications using the comprehensive complications index. Hpb. 2019; 21(12):1761-72. Available from. https://doi.org/10.1016/j.hpb.2019.04.006.

Milanović Z, Pantelić S, Trajković N, Sporiš G, Kostić R, James N. Age-related decrease in physical activity and functional fitness among elderly men and women. Clin Interv Aging. 2013;8:549-56.

Moran J, Wilson F, Guinan E, McCormick P, Hussey J, Moriarty J. Role of cardiopulmonary exercise testing as a risk-assessment method in patients undergoing intra-abdominal surgery: a systematic review. $\mathrm{Br} J$ Anaesth. 2016a;116(2):177-91.

Moran J, Wilson F, Guinan E, McCormick P. Hussey J, Moriarty J. The preoperative use of field tests of exercise tolerance to predict postoperative outcome in intra-abdominal surgery: a systematic review. J Clin Anesth. 2016b;35:446-55. Available from. https://doi.org/10.1016/j.jclinane.2016.09.019.

Mungovan SF, Huijbers BP, Hirschhorn AD, Patel MI. Relationships between perioperative physical activity and urinary incontinence after radical prostatectomy: an observational study. BMC Urol. 2013;13:1-9.

Pearse RM, Moreno RP, Bauer P, Pelosi P, Metnitz P, Spies C, et al. Mortality after surgery in Europe: a 7 day cohort study. Lancet. 2012;380(9847):1059-65. Available from. https://doi.org/10.1016/S0140-6736(12)61148-9.

Pinto A, Faiz O, Davis R, Almoudaris A, Vincent C. Surgical complications and their impact on patients' psychosocial well-being: a systematic review and meta-analysis. BMJ Open. 2016;6(2):e007224.

Portney G, Watkins P. Foundations of clinical research: applications to practice. New Jersey Pearson Educ. 2009;685-726.

Prince SA, Adamo KB, Hamel ME, Hardt J, Connor Gorber S, Tremblay M. A comparison of direct versus self-report measures for assessing physical activity in adults: a systematic review. Int J Behav Nutr Phys Act. 2008:5:56.

Probst VS, Hernandes NA, Teixeira DC, Felcar JM, Mesquita RB, Gonalves CG, et al. Reference values for the incremental shuttle walking test. Respir Med. 2012; 106(2):243-8

R Development Core Team. R: a language and environment for statistical computing. Vienna: R Foundation for Statistical Computing; 2013. Available from: http://www.r-project.org

Raill T. What is the effect of age on pancreatic resection? Adv Surg. 2009;43:23349 Available from: https://www.ncbi.nlm.nih.gov/pmc/articles/PMC3624763/ pdf/nihms412728.pdf.

Sasaki JE, John D, Freedson PS. Validation and comparison of ActiGraph activity monitors. J Sci Med Sport. 2011;14(5):411-6. Available from. https://doi.org/1 0.1016/j.jsams.2011.04.003. 
Simões CM, Carmona MJC, Hajjar LA, Vincent JL, Landoni G, Belletti A, et al. Predictors of major complications after elective abdominal surgery in cancer patients. BMC Anesthesiol. 2018;18(1):1-8.

Singh S, Morgan M, Scott S, Walters D, Hardman A. Development of a shuttle walking test of disability in patients with chronic airflow obstruction. Thorax. 1992:47:1019-24

Snowden CP, Prentis JM, Anderson HL, Roberts DR, Randles D, Renton M, et al. Submaximal cardiopulmonary exercise testing predicts complications and hospital length of stay in patients undergoing major elective surgery. Ann Surg. 2010;251(3):535-41.

Stanojevic S, Wade A, Stocks J. Reference values for lung function: past, present and future. Eur Respir J. 2010;36(1):12-9.

Steffens D, Beckenkamp PR, Young J, Solomon M, da Silva TM, Hancock MJ. Is preoperative physical activity level of patients undergoing cancer surgery associated with postoperative outcomes? A systematic review and metaanalysis. Eur J Surg Oncol. 2019;45(4):510-8. Available from. https://doi.org/1 0.1016/.j.jso.2018.10.063.

Straatman J, Cuesta MA, De Lange-De Klerk ESM, Van Der Peet DL. Hospital costanalysis of complications after major abdominal surgery. Dig Surg. 2015;32(2): $150-6$.

Troiano RP, Berrigan D, Dodd KW, Mâsse LC, Tilert T, Mcdowell M. Physical activity in the United States measured by accelerometer. Med Sci Sports Exerc. 2008:40(1):181-8.

Van Beijsterveld CA, Bongers BC, Den Dulk M, Van Kuijk SMJ, Dejong KCH, Van Meeteren NLU. The association between preoperative physical functioning and short-term postoperative outcomes: a cohort study of patients undergoing elective hepatic resection. HPB. 2019;21(10):1362-70. Available from. https://doi.org/10.1016/j.hpb.2019.02.009.

Van der Meij E, Van der Ploeg HP, Van Den Heuvel B, Dwars BJ, Meijerink WJHJ, Bonjer $\mathrm{HJ}$, et al. Assessing pre- and postoperative activity levels with an accelerometer: a proof of concept study. BMC Surg. 2017;17(1):1-10.

Vassbakk-Brovold K, Kersten C, Fegran L, Mjåland O, Mjåland S, Seiler S, et al. Cancer patients participating in a lifestyle intervention during chemotherapy greatly over-report their physical activity level: a validation study. BMC Sports Sci Med Rehabil. 2016;8(1):1-9. Available from. https://doi.org/10.1186/s131 02-016-0035-z.

Weggemans RM, Backx FJG, Borghouts L, Chinapaw M, Hopman MTE, Koster A et al. The 2017 Dutch Physical Activity Guidelines. Int I Behav Nutr Phys Act. 2018;15(1):1-12.

WHO. Global health risks - mortality and burden of disease attributable to selected major risks. 2009. Available from: http://www.who.int/healthinfo/ global_burden_disease/GlobalHealthRisks_report_full.pdf

Wong-Lun-Hing EM, van Dam RM, van Breukelen GJP, Tanis PJ, Ratti F, van Hillegersberg R, et al. Randomized clinical trial of open versus laparoscopic left lateral hepatic sectionectomy within an enhanced recovery after surgery programme (ORANGE II study). Br J Surg. 2017;104(5):525-35.

Yohai V, Stabel W, Zamar R. A procedure for robust estimation and inference in linear regression, Directions in RObust Statistics and Diagnostics Part II; 1991. p. $365-74$.

\section{Publisher's Note}

Springer Nature remains neutral with regard to jurisdictional claims in published maps and institutional affiliations.

Ready to submit your research? Choose BMC and benefit from:

- fast, convenient online submission

- thorough peer review by experienced researchers in your field

- rapid publication on acceptance

- support for research data, including large and complex data types

- gold Open Access which fosters wider collaboration and increased citations

- maximum visibility for your research: over $100 \mathrm{M}$ website views per year

At BMC, research is always in progress.

Learn more biomedcentral.com/submissions 